\title{
The role of tonicity responsive enhancer sites in the transcriptional regulation of human hsp70-2 in response to hypertonic stress
}

\author{
Jee-In Heo ${ }^{1}$, Mi-Suk Lee ${ }^{1}$, \\ Jeong-Hyun $\mathrm{Kim}^{2}$, Jae-Seon Lee ${ }^{3}$, \\ Jaebong Kim ${ }^{1}$, Jae-Bong Park', \\ Jae-Yong Lee ${ }^{1}$, Jeong A. Han ${ }^{4}$ \\ and Jong-II $\mathrm{Kim}^{1,5}$ \\ ${ }^{1}$ Department of Biochemistry \\ Hallym University College of Medicine \\ Chuncheon 200-702, Korea \\ ${ }^{2}$ ILCHUN Molecular Medicine Institute \\ Seoul National University College of Medicine \\ Seoul 110-799, Korea \\ ${ }^{3}$ Laboratory of Functional Genomics \\ Korea Institute of Radiological and Medical Sciences \\ Seoul 139-706, Korea \\ ${ }^{4}$ Department of Biochemistry and Molecular Biology \\ Kangwon National University College of Medicine \\ Chuncheon 200-701, Korea \\ ${ }^{5}$ Corresponding author: Tel, 82-33-248-2540; \\ Fax, 82-33-244-8425; E-mail, jongil@hallym.ac.kr
}

Accepted 2 June 2006

Abbreviations: HSP, heat shock protein; Hsp70, heat shock protein $70 \mathrm{kDa}$; TonE, tonicity responsive enhancer; TonEBP, TonE binding protein

\begin{abstract}
The inducible $70 \mathrm{kDa}$ heat shock proteins (Hsp70) in mice are encoded by two almost identical genes, $h s p 70.1$ and $h s p 70.3$. Studies have found that only hsp70.1 is induced by hypertonic stress while both $h s p 70.1$ and hsp70.3 genes are expressed in response to heat shock stress. It is unclear if the human counterparts, hsp70-2 and hsp70-1, are differentially regulated by heat shock and osmotic stress. This study found that only hsp70-2 was induced by hypertonic stress in human embryonic kidney epithelial cells and fibroblasts, while heat shock stress induced both $h s p 70-1$ and $h s p 70-2$. The human hsp70-2 promoter region contains three TonE (tonicity-responsive enhancer) sites, which were reported to play an important role in the response to hypertonicity. When the reporter plasmids contain -
\end{abstract}

ing different parts of the $5^{\prime}$ flanking region of $h s p 70-2$ were transfected into human embryonic kidney epithelial cells or fibroblasts, one TonE site at -135 was found to play a key role in the response to hypertonicity. The inactivation of the TonE site using site-directed mutagenesis led to the complete loss of induction by hypertonicity, which demonstrates the essential role of the TonE site. This suggests that the TonE site and the TonEBP (TonE binding protein) are the major regulators for the cellular response against high osmolarity in human kidney tissue.

Keywords: HSP70 heat-shock proteins; heat-shock proteins; stress; transcription factors; gene expression regulation

\section{Introduction}

A wide range of harmful conditions, such as heat shock, alcohol, inhibitors of the energy metabolism, heavy metals, amino acid analogues, oxidative stress, fever, inflammation or ischemia, cause unique stress responses in a cell, which involves the induction of the heat shock proteins (HSPs) (Morimoto et al., 1992; Jolly and Morimoto, 2000). The HSPs consist of six major families, Hsp100, Hsp90, Hsp70, Hsp60, Hsp40 and small heat shock proteins (Fink, 1999). The Hsp70 family is the most highly conserved among the HSP families, and can be found in most organisms ranging from bacteria to plants and animals (Beere and Green, 2001). Hsp70, like other HSPs, acts as a molecular chaperone that protects cells from stress by its ability to interact with denatured proteins, to prevent aggregation, and to restore their original structure and function (Fink, 1999; Beere and Green, 2001). Hsp70 can also protect cells from apoptotic stimuli, including DNA damage, UV irradiation, serum withdrawal and chemotherapeutic agents (Jaattela et al., 1992; Seo et al., 1996; Mosser et al., 1997). Direct interaction with Apaf-1 and the prevention of procaspase- 9 activation in the apoptosome complex is one of the major mechanisms by which Hsp70 inhibits the apoptotic process (Beere et al., 2000; Li et al., 2000; Saleh et al., 2000).

To date, more than seven members of the $h s p 70$ family have been identified in the murine genome. 
Among them, two major inducible hsp70 genes, hsp70.1 (hspa1b) and hsp70.3 (hspa1a) are clustered in a tandem array on chromosome 17, and have almost identical coding sequences. While many types of stress such as heat shock, heavy metals, and amino acids analogues induce both hsp70.1 and hsp70.3 simultaneously, hypertonic stress has been found to induce $h s p 70.1$ selectively (Tanaka et al., 1988; Lee and Seo, 2002; Woo et al., 2002).

The cells in the renal medulla are routinely challenged with ten-fold variations in the extracellular osmolarity, and the adaptation of these cells to extreme conditions is essential for maintaining the normal kidney function (Dmitrieva and Burg, 2005). Several reports have suggested the possibility that hypertonic stress and $h s p 70$ induction may be related to the human kidney disease process (Sheikh-Hamad et al., 2001; Shim et al., 2002; Dmitrieva and Burg, 2005). However, the induction of $h s p 70$ by hypertonic stress as well as its protective role in human cell is unclear. The human genome contains two similar isoforms of inducible hsp70 genes, $h s p 70-1$ and $h s p 70-2$, which are the counterparts of murine $h s p 70.3$ and $h s p 70.1$, respectively. Although the human and mouse $h s p 70$ genes have highly conserved coding sequences, the sequence homology in the promoter region is quite low compared with the coding region. This study investigated whether or not human hsp70-1 and hsp70-2 are differentially regulated by hypertonic stress, and which part of the promoter region is responsible for this differential expression.

\section{Materials and Methods}

\section{Cell culture and treatment}

The human embryonic kidney epithelial line 293T (HEK293T) and human embryonic fibroblast (HEF) cells were cultured in Dulbecco's modified Eagle's medium, $10 \%$ fetal bovine serum, and $1 \%$ streptomycin/penicillin in a $5 \% \mathrm{CO}_{2}$ incubator. For the heat shock experiments, the cells were heated to $42^{\circ} \mathrm{C}$ for $2 \mathrm{~h}$, then kept in a $\mathrm{CO}_{2}$ incubator at $37^{\circ} \mathrm{C}$ for the indicated times. The hypertonic medium used for the hypertonic stress experiments were made by adding $\mathrm{NaCl}$ at the indicated concentrations, and the cells were exposed to the hypertonic medium for 6 to $24 \mathrm{~h}$.

\section{Western blot analysis}

The cells were lysed for $30 \mathrm{~min}$ at $4{ }^{\circ} \mathrm{C}$ in a lysis buffer (50 mM Tris-Cl, pH 7.4, $150 \mathrm{mM} \mathrm{NaCl}, 1 \%$ Nonidet P-40, $0.25 \%$ sodium deoxycholate, $1 \mathrm{mM}$
EDTA) with a protease inhibitor cocktail (Sigma) and phosphatase inhibitors ( $1 \mathrm{mM} \mathrm{Na}_{3} \mathrm{VO}_{4}$ and $1 \mathrm{mM}$ $\mathrm{NaF}$ ). The proteins were quantified using a Bio-Rad protein assay according to the manufacturer's instructions. Forty micrograms of the protein were boiled in sample buffer for $5 \mathrm{~min}$ and then loaded onto a $10 \%$ SDS-polyacrylamide gel. After electrophoresis for $2 \mathrm{~h}$ at $100 \mathrm{~V}$, the proteins were transferred from the gel to an Immun-Blot PVDF membrane (Bio-Rad) at $80 \mathrm{~V}$ for $40 \mathrm{~min}$. The membranes were then blocked with $5 \%$ skimmed milk. In order to detect Hsp70 or Hsc70, the membranes were incubated with the antibodies at a 1:1000 dilution for 1 $h$ in $1 \times$ TBST. The mouse anti-Hsp70 monoclonal and rabbit anti-Hsc70 polyclonal antibodies were obtained from Stressgen. The membranes were then incubated with the secondary antibody conjugated with anti-mouse IgG-horseradish peroxidase or anti-rabbit lgG-horseradish peroxidase. The Hsp70 and Hsc70 levels were determined using an ECL system (Amersham Biosciences).

\section{Reverse transcription (RT)-PCR}

The total RNA was extracted from the HEK293T and HEF cells with Trizol reagent (Life technologies). Two $\mu \mathrm{g}$ of the total RNA was reverse transcribed using a SuperScript first-strand synthesis system (Life Technologies) according to the manufacturer's instructions. After the reverse transcription reaction, PCR was performed using a PCR Supermix high fidelity kit (Life Technologies) under the following conditions: $94^{\circ} \mathrm{C}$ for $5 \mathrm{~min}$; followed by 35 cycles of $94^{\circ} \mathrm{C}$ for $30 \mathrm{~s}, 55^{\circ} \mathrm{C}$ for $30 \mathrm{~s}$, and $72^{\circ} \mathrm{C}$ for $30 \mathrm{~s}$; followed by $10 \mathrm{~min}$ at $72^{\circ} \mathrm{C}$. The PCR products were resolved on $1.5 \%$ agarose gels. The following primers were used for PCR amplification: 5'-AGC TGG AGC AGG TGT GTA AC-3' (sense) and 5'-GAA GGT GGC AGT GTT GAT TC-3' (antisense) to identify the transcripts of human hsp70-2. The human $h s p 70-1$ primers were 5'-AGC TGG AGC AGG TGT GTA AC-3' (sense) and 5'-CTC CTG ACC TCA AGT GAT CC-3' (antisense).

\section{Cloning of hsp70-2 promoter constructs}

The human $h s p 70-2$ and $h s p 70-1$ promoters containing different lengths of the promoter regions were cloned into the pGL3 basic vector (Promega) to generate the luciferase reporter constructs (Figure 3A).

\section{Transfection and luciferase assay}

The day before transfection, the HEK293T and HEF cells were seeded at 90 to $95 \%$ confluence in 60-mm culture dishes. The hsp70-2 promoter con- 
structs were transfected into the HEK293T and HEF cells using Lipofectamin 2000 (Life Technologies). Each reporter construct $(4 \mu \mathrm{g})$ was transfected with $0.4 \mu \mathrm{g}$ of the control plasmid containing the $\beta$ galactosidase gene. After transfection, the cells were maintained in an isotonic medium for $24 \mathrm{~h}$ and then switched to either a hypertonic medium or were maintained in the isotonic medium for $24 \mathrm{~h}$. For heat shock treatment, the transfected cells were maintained at $37^{\circ} \mathrm{C}$ for $24 \mathrm{~h}$, shifted to $42^{\circ} \mathrm{C}$ for $2 \mathrm{~h}$, and kept in $\mathrm{CO}_{2}$ incubator at $37^{\circ} \mathrm{C}$ for $6 \mathrm{~h}$ prior to analysis. The luciferase activity in the extract of the transfected cells was determined using a commercial kit, Luciferase Assay Reagent (Promega), and the $\beta$-galactosidase activity was determined using a $\beta$-galactosidase enzyme assay system (Promega). For each sample, the luciferase activity was divided by the $\beta$-galactosidase activity to correct for the transfection efficiency.

\section{Site directed mutagenesis}

The one TonE site (the most proximal one) in the hsp70-2 promoter was inactivated by site-directed mutagenesis using a QuickChange Site-Directed Mutagenesis kit (Stratagene) according to the manufacturer instructions. TGGTGGAAAAGTCCAGCT (TonE site is underlined) to TGGTGtccccGTCCAGCT (Miyakawa et al., 1999). The mutation was verified by sequencing.

A

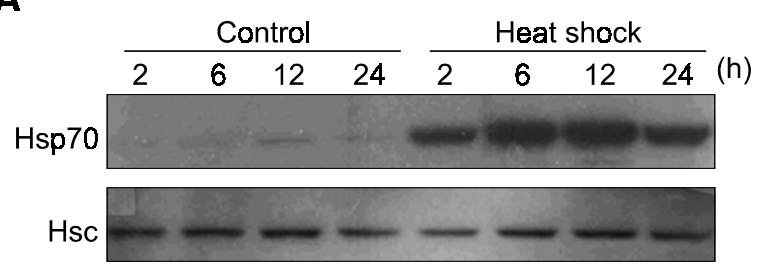

B

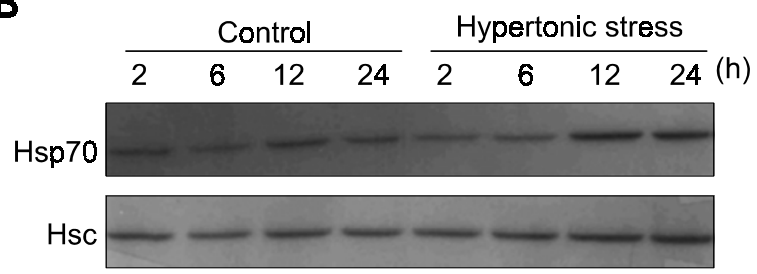

Figure 1. Induction of $\mathrm{Hsp} 70$ by heat shock and hypertonic stress in HEF cells. The cells were heat shocked $\left(A ; 42^{\circ} \mathrm{C}\right.$ for $2 \mathrm{~h}$ followed by recovery at $37^{\circ} \mathrm{C}$ for the indicated time periods), or exposed to a hypertonic medium ( $\mathrm{B}$; made by addition of $100 \mathrm{mM} \mathrm{NaCl}$ ) for the indicated time periods. $40 \mu \mathrm{g}$ of the protein from the cell lysate was then used for Western blot analysis of Hsp70 and Hsc70.

\section{Results}

\section{Human $h s p 70-2$, but not $h s p 70-1$, was induced by hypertonic stress}

The level of Hsp70 induction in response to heat shock stress and hypertonic stress in human embryonic fibroblasts (HEF) was examined by Western blotting. The Hsp70 protein level was up to 3 times higher when the osmolality of the culture medium was increased by $100 \mathrm{mM} \mathrm{NaCl}$ for $12 \mathrm{~h}$ (Figure 1B). Heat shock also increased the Hsp70 protein level up to 15 times within $6 \mathrm{~h}$ (Figure $1 \mathrm{~A}$ ). The expression of the noninducible isoform, Hsc70, was unaffected by heat or hypertonicity.

In order to examine the different transcriptional regulation of human $h s p 70-2$ and $h s p 70-1$ in response to heat shock stress and hypertonic stress, the specific RT-PCR primers were designed from the divergent 3'untranslated regions, as described in Materials and Methods. RT-PCR using the hsp70-2 specific primers revealed strong induction of hsp70-2 mRNA in the HEF by both heat shock and hypertonic stress. On the other hand, hsp70-1 mRNA was induced by heat shock stress only (Figure 2B). These results were also confirmed in the human embryonic kidney epithelial cell line (HEK293T) (Figure 2A).

\section{About-250 bp region in the hsp70-2 promoter was responsible for the induction of $h s p 70$ by hypertonic stress}

The human $h s p 70-2$ promoter region contains three TonE (tonicity-responsive enhancer) sites, which have been reported to play an important role in the response to hypertonicity (Woo et al., 2002).

In order to investigate the roles of each TonE site, reporter plasmids were constructed containing different parts of the 5' flanking region of $h s p 70-2$, 1-TonE-L-Luc (from -1505 to -58), 2-TonE-Luc (from -3261 to -58 ) and 3-TonE-Luc (from -3700 to -58 ), which contain one, two and three TonE sites, respectively.

When the cells were transfected with these reporter plasmid constructs, all three showed increased luciferase expression in response to hypertonic stress in the HEF (Figure 3B) and in HEK293T cells (Figure $3 \mathrm{C}$ ). In contrast, the hsp70-1 promoter, which contains no TonE sites, was not induced by hypertonic stress (Figure 4A).

Heat shock element in hsp70-2 promoter region is well known to be responsible for the induction by various environmental stresses. Therefore, another reporter plasmid was constructed: 1-TonE-S-Luc (from -297 to -58), which contains one TonE site but not the heat shock element (Figure $3 \mathrm{~A}$ ). Figure 4 
A
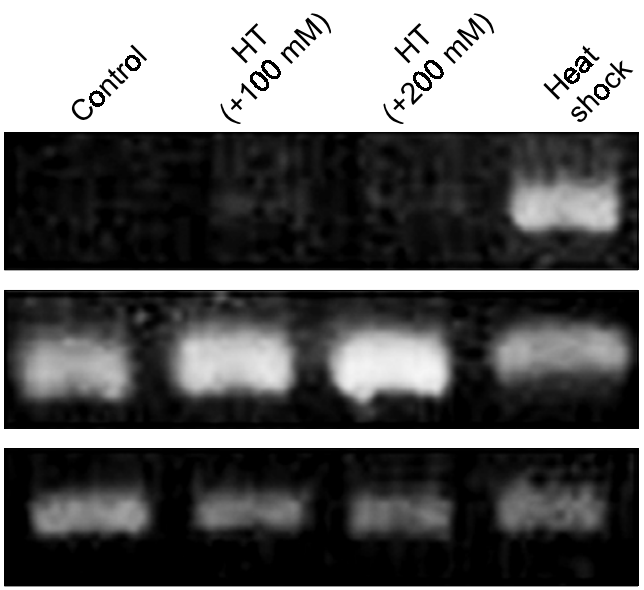

B

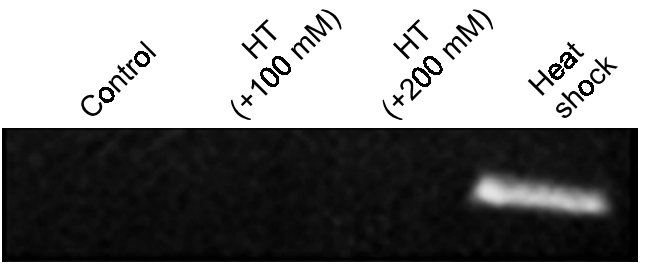

Hsp70-2

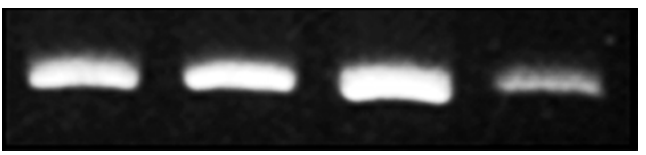

GAPDH

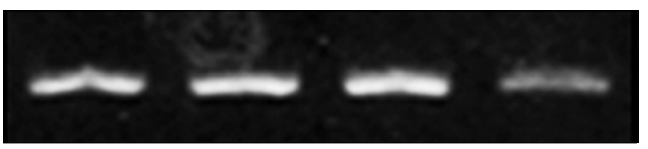

Figure 2. RT-PCR to detect the expression of specific human hsp70 isoforms. HEK293T (A) and HEF cells (B) The cells were exposed to heat shock or the hypertonic medium (HT). The total RNA was isolated and the samples $(2 \mu \mathrm{g})$ were analyzed by RT-PCR using the specific primers made from a unique sequence of the divergent 3'UTR of each hsp70 gene. The RT-PCR product was resolved on 1.5\% agarose gel and visualized by Et-Br staining.

A

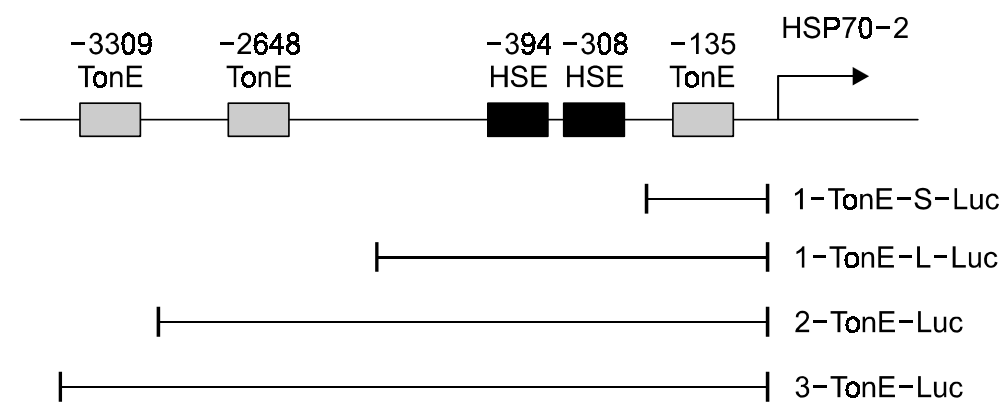

B

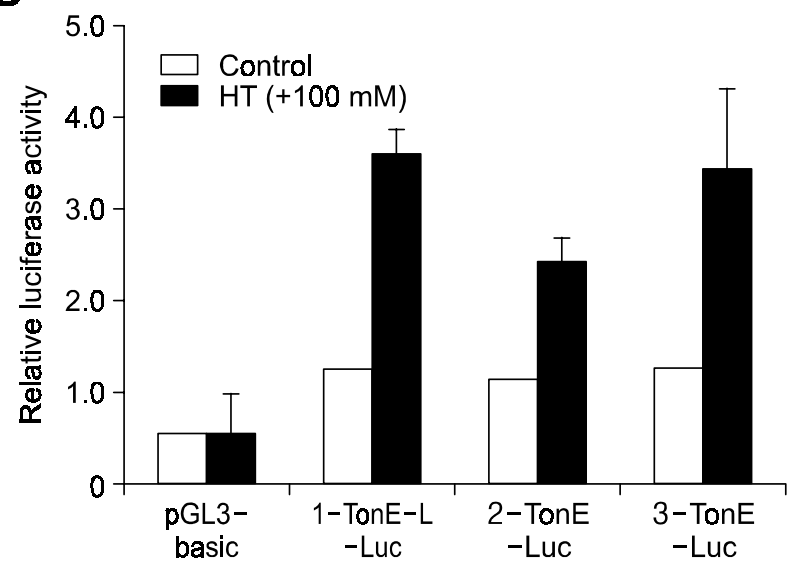

C

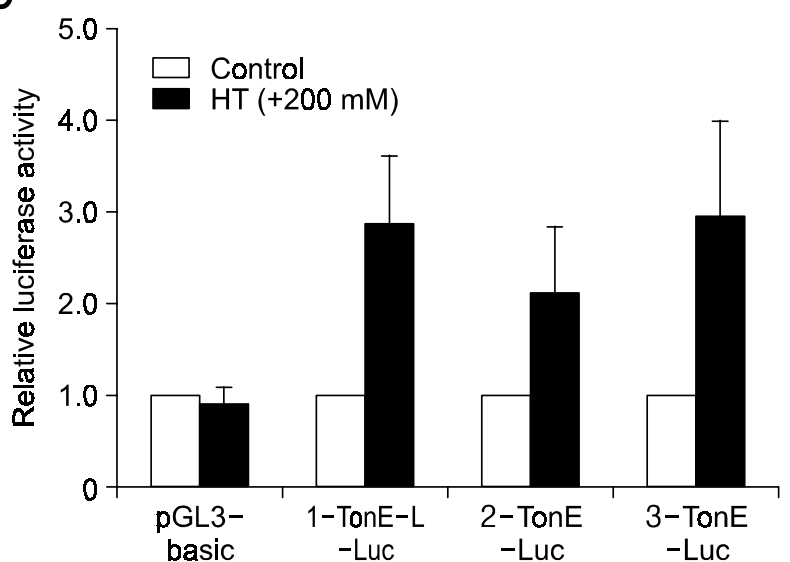

Figure 3. The transcriptional activation of different hsp70-2 promoter regions in response to hypertonicity. (A) Construct of the human hsp70-2 promoter. HEF (B) and HEK293T (C) cells were transiently transfected with $4 \mu \mathrm{g}$ of each reporter construct along with $0.4 \mu \mathrm{g}$ of the control plasmid containing the $\beta$-galactosidase gene. After the transfected cells were cultured in hypertonic medium (HT) for $24 \mathrm{~h}$, the luciferase activities were measured, and normalized by the $\beta$-galactosidase activity. 
A

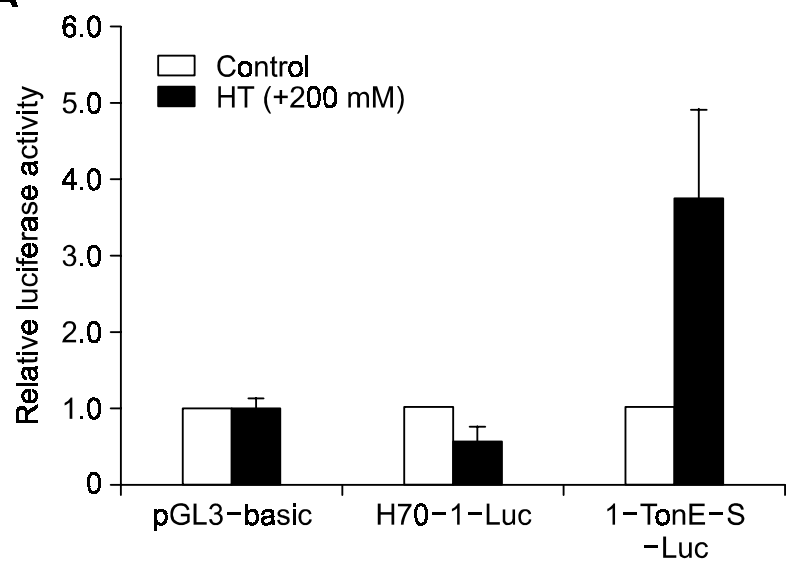

B

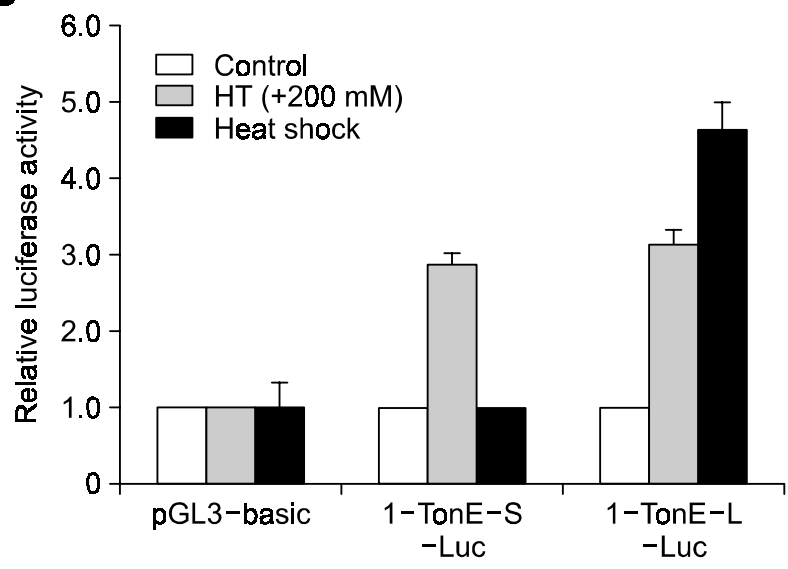

Figure 4. The transcriptional activation of 1-TonE-S by hypertonicity but not by heat shock. The HEK293T cells were transiently transfected with $4 \mu \mathrm{g}$ of each reporter construct along with $0.4 \mu \mathrm{g}$ of the control plasmid containing the $\beta$-galactosidase gene. After the transfected cells had been treated with hypertonic medium $(\mathrm{HT})$ or heat shock, the luciferase activities were measured, and normalized to the $\beta$-galactosidase activity.

shows that 1-TonE-S-Luc has lost the heat shock response but still showed increased expression as a response to hypertonic stress similar to 1 -TonE-LLuc.

\section{One TonE site was necessary for the hypertonic stress response of human hsp70-2}

Previous data (Figure $3 B$ and $C$ ) showed that each construct had a similar level of induction by hypertonicity. This suggested that one TonE at -135 is sufficient to express the $h s p 70$ genes in response to hypertonicity. In order to confirm the role of the TonE site in 1-TonE-S, a point mutation was introduced at the TonE site, as shown in Figure 5A. A mutation of the TonE site led to the complete loss of induction by hypertonicity, indicating that the proximal TonE site is essential for the response to hypertonicity in the human hsp70-2 promoter (Figure 5B).

\section{Discussion}

Two almost identical genes, hsp70.1 and hsp70.3, encode major inducible $\mathrm{Hsp} 70$ proteins in mice. It has been previously shown that $h s p 70.1$ is responsible for inducing $\mathrm{Hsp} 70$ in response to hypertonic stress in mice, and plays a cytoprotective role against the stress (Lee and Seo, 2002; Shim et al., 2002). Woo et al. reported that the transcriptional activator Tonicity-responsive enhancer (TonE) binding protein (TonEBP) regulates the induction of hsp70.1 in response to hypertonic stress (Woo et al., 2002). We reasoned that the induction of human hsp70 by hypertonic stress might have a different regulatory mechanism from that of murine hsp70.
First, the promoter region of human $h s p 70-2$ has a different organization of regulatory elements from that of their murine counterpart, hsp70.1. There are four TonE sites in the murine $h s p 70.1$ promoter region at $-1070,-2326,-3698$, and -3715 , and only one of them has a reverse orientation. Woo et al. reported that three of the four TonE sites (TonEA, TonEB, and TonED) additively contribute to the induction caused by hypertonicity (Woo et al., 2002). It was found that human hsp70-2 promoter contains three possible TonE sites (Figure 3A), which meet the consensus sequence (TGGAAANNYNY; (Rim et al., 1998). However, all three sites have reverse orientation. There is insufficient information regarding whether or not the reverse-oriented TonE sites work in similar manner to the right oriented one. Therefore, this study examined whether or not human $h s p 70-2$ could be induced by hypertonicity, and the extent to which the TonE sites contribute to the induction.

The second interesting point in the promoter regions of the human $h s p 70$ genes is that $h s p 70-1$ also has two possible TonE sites at -633 and -740 , in the right and reverse orientations, respectively. Murine $h s p 70.3$, which is the counterpart of human hsp70-1, is not induced by hypertonicity (Lee and Seo, 2002; Woo et al., 2002). However, the very close location of the two TonE consensus sequences near the transcription start site suggests the possibility of human $h s p 70-1$ induction by hypertonic stress.

Figure 2 and Figure 4A clearly show that human hsp70-1 cannot be induced by hypertonic stress in at least two human cell lines, HEF and HEK293T. The reason why the two candidate TonE sites in hsp70-1 
A

$-135$

- TGGTGGAAAAGTCCAGCT — 1-TonE-S

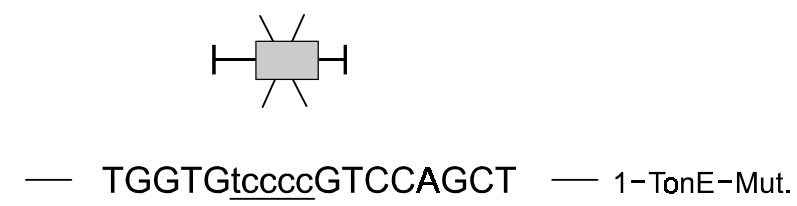

B

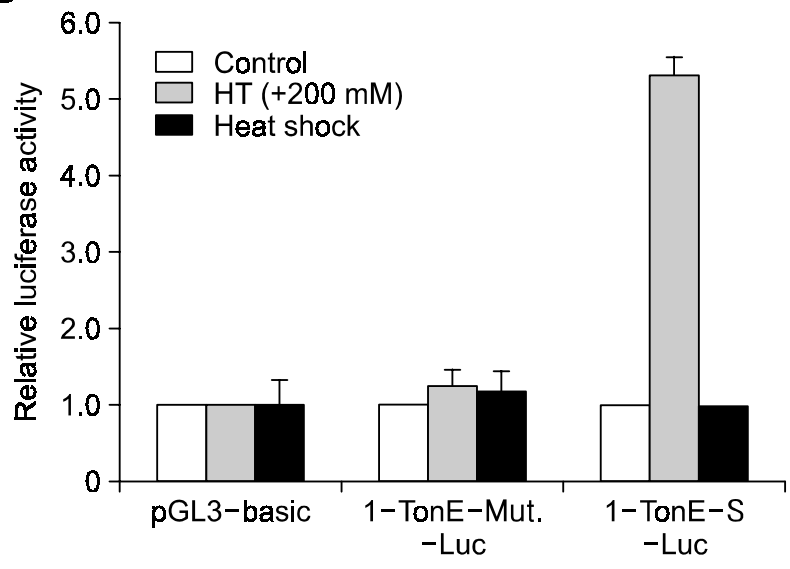

Figure 5. Loss of induction by the inactivation of one TonE site in the hsp70-2 promoter. (A) 1-TonE-S in the reporter plasmid was inactivated by site-directed mutagenesis. (B) The HEK293T cells were transiently transfected with $4 \mu \mathrm{g}$ of each reporter construct along with $0.4 \mu \mathrm{g}$ of the control plasmid containing the $\beta$-galactosidase gene. After the transfected cells had been treated with hypertonic $(\mathrm{HT})$ medium or heat shock, the luciferase activities were measured, and normalized to the $\beta$-galactosidase activity.

did not work properly is unclear. One possibility is that $h s p 70-1$ is located very close to another $h s p 70$ isoform, hsp70-hom (hspa1l), in the head to head orientation, and the TonE sites may have a major influence on $h s p 70-h o m$, but not $h s p 70-1$. An examination of the hsp70-hom level after hypertonic stimulation or the electrophoretic mobility shift assay (EMSA) using each candidate TonE site will be needed to determine the role of the possible TonE sites in the hsp70-1 promoter.

The way each TonE site contributes to the induction of human $h s p 70-2$ was quite different from the murine one. The three TonE sites in the mouse $h s p 70.1$ promoter worked additively, and the inactivation of any one site led to a significant and proportional decrease in the level of induction, even though they were located as far as 3,715 base pairs in the upstream region (Woo et al., 2002). However, our result revealed that the removal of two distant TonE sites had no influence on the level of induction (Figure 2), and the inactivation of one TonE site caused the complete loss of induction, indicating that only one TonE site at -135 plays a major role in the transcriptional regulation of the human $\mathrm{Hsp} 70$ protein.

We also investigated whether or not mechanisms other than transcriptional regulation can control the Hsp70 level after hypertonic stress. Alfieri et al. reported that the stability of mouse $h s p 70$ mRNA can be altered by hypertonicity, and Zhao et al. showed that the cis-acting $A+U$ rich elements (ARE) in the 3'-untranslated region (UTR) of $h s p 70.1$ controls the mRNA stability (Alfieri et al., 2002; Zhao et al., 2002). We found that human hsp70-2 mRNA had two AUUUA sequences in its 3' UTR. However, when the 3'-UTR fragments of human hsp70-2 were incorporated into the luciferase reporter construct and the luciferase activity was measured, there was no difference in the luciferase level before and after hypertonic stress (data not shown). This suggests that the TonE site and the TonEBP (TonE binding protein) are the major regulators for the cellular response against a high osmolality in human kidney cells.

It was previously reported that the selective disruption of $h s p 70.1$ in mice led to increased apoptosis in the renal medulla after osmotic stress (Shim et al., 2002). Mammalian renal medullary cells are normally exposed to a high osmotic environment, and any defect in the defense mechanism against osmotic stress may lead to serious kidney problems (Dmitrieva and Burg, 2005). There is no evidence that a mutation or inactivation of Hsp70 is associated with human kidney diseases. However, Hsp70 is down-regulated during the aging process in animal model (Heydari et al., 1994). The down-regulation of Hsp70 in aged human cells has also been reported in some tissues or cell culture systems (Muramatsu et al., 1996; Gutsmann-Conrad et al., 1998; Jin et al., 2004; Jurivich et al., 2005). Therefore, further investigation will be needed to determine if the Hsp70 level decreases in aged human renal medullary cells, and whether or not the level of Hsp70 has any relationship with the decreased renal function. Furthermore, research into the relationship between a single nucleotide polymorphism (SNP) in the promoter region of the human $h s p 70$ gene and human complex diseases including a renal dysfunction will be needed. It is believed that these results will provide an important information for 
elucidating the mechanisms underlying the protection of renal cells under a hyperosmotic environment, as well as human kidney diseases related to chronic stress or aging.

\section{Acknowledgement}

This work was supported by grants from Hallym University Research Fund, 2002 (HRF-2002-53), and in part by the Korea Research Foundation Grant funded by the Korean Gonvernment (MEEHRD, R08-2003-000-10372-0).

\section{References}

Alfieri RR, Bonelli MA, Petronini PG, Borghetti AF. Stabilization of hsp70 mRNA on prolonged cell exposure to hypertonicity. Biochim Biophys Acta 2002;1592:135-40

Beere HM, Wolf BB, Cain K, Mosser DD, Mahboubi A, Kuwana T, Tailor P, Morimoto RI, Cohen GM, Green DR. Heat-shock protein 70 inhibits apoptosis by preventing recruitment of procaspase-9 to the Apaf-1 apoptosome. Nat Cell Biol 2000;2: 469-75

Beere HM, Green DR. Stress management - heat shock protein-70 and the regulation of apoptosis. Trends Cell Biol 2001;11:6-10

Dmitrieva NI, Burg MB. Hypertonic stress response. Mutat Res 2005;569:65-74

Fink AL. Chaperone-mediated protein folding. Physiol Rev 1999;79:425-49

Gutsmann-Conrad A, Heydari AR, You S, Richardson A. The expression of heat shock protein 70 decreases with cellular senescence in vitro and in cells derived from young and old human subjects. Exp Cell Res 1998;241:404-13

Heydari AR, Takahashi R, Gutsmann A, You S, Richardson A. Hsp70 and aging. Experientia 1994;50:1092-8

Jaattela M, Wissing D, Bauer, PA, Li GC. Major heat shock protein hsp70 protects tumor cells from tumor necrosis factor cytotoxicity. Embo J 1992;11:3507-12

Jin X, Wang R, Xiao C, Cheng L, Wang F, Yang L, Feng T, Chen M, Chen S, Fu X, Deng J, Wang R, Tang F, Wei Q, Tanguay $\mathrm{RM}, \mathrm{Wu} \mathrm{T}$. Serum and lymphocyte levels of heat shock protein 70 in aging: a study in the normal Chinese population. Cell Stress Chaperones 2004;9:69-75

Jolly C, Morimoto RI. Role of the heat shock response and molecular chaperones in oncogenesis and cell death. J Natl Cancer Inst 2000;92:1564-72

Jurivich DA, Choo M, Welk J, Qu L, Han K, Zhou X. Human aging alters the first phase of the molecular response to stress in T-cells. Exp Gerontol 2005;40:948-58
Lee JS, Seo JS. Differential expression of two stress-inducible hsp70 genes by various stressors. Exp Mol Med 2002;34: $131-6$

Li CY, Lee JS, Ko YG, Kim JI, Seo JS. Heat shock protein 70 inhibits apoptosis downstream of cytochrome c release and upstream of caspase-3 activation. J Biol Chem 2000;275: 25665-71

Miyakawa H, Rim JS, Handler JS, Kwon HM. Identification of the second tonicity-responsive enhancer for the betaine transporter (BGT1) gene. Biochim Biophys Acta 1999;1446:359-64

Morimoto RI, Sarge KD, Abravaya K. Transcriptional regulation of heat shock genes. A paradigm for inducible genomic responses. J Biol Chem 1992;267:21987-90

Mosser DD, Caron AW, Bourget L, Denis-Larose C, Massie, $B$. Role of the human heat shock protein hsp70 in protection against stress-induced apoptosis. Mol Cell Biol 1997;17: 5317-27

Muramatsu T, Hatoko M, Tada H, Shirai T, Ohnishi T. Age-related decrease in the inductability of heat shock protein 72 in normal human skin. Br J Dermatol 1996;134:1035-8

Rim JS, Atta MG, DahI SC, Berry GT, Handler JS, Kwon HM. Transcription of the sodium/myo-inositol cotransporter gene is regulated by multiple tonicity-responsive enhancers spread over 50 kilobase pairs in the 5 '-flanking region. J Biol Chem 1998;273:20615-21

Saleh A, Srinivasula SM, Balkir L, Robbins PD, Alnemri ES. Negative regulation of the Apaf-1 apoptosome by Hsp70. Nat Cell Biol 2000;2:476-83

Seo JS, Park YM, Kim JI, Shim EH, Kim CW, Jang JJ, Kim SH, Lee WH. T cell lymphoma in transgenic mice expressing the human Hsp70 gene. Biochem Biophys Res Commun 1996; 218:582-7

Sheikh-Hamad D, Nadkarni V, Choi YJ, Truong LD, Wideman C, Hodjati R, Gabbay KH. Cyclosporine A inhibits the adaptive responses to hypertonicity: a potential mechanism of nephrotoxicity. J Am Soc Nephrol 2001;12:2732-41

Shim EH, Kim JI, Bang ES, Heo JS, Lee JS, Kim EY, Lee JE, Park WY, Kim SH, Kim HS, Smithies O, Jang JJ, Jin DI, Seo JS. Targeted disruption of hsp70.1 sensitizes to osmotic stress. EMBO Rep 2002;3:857-61

Tanaka K, Jay G, Isselbacher KJ. Expression of heat-shock and glucose-regulated genes: differential effects of glucose starvation and hypertonicity. Biochim Biophys Acta 1988;950: 138-46

Woo SK, Lee SD, Na KY, Park WK, Kwon HM. TonEBP/NFAT5 stimulates transcription of HSP70 in response to hypertonicity. Mol Cell Biol 2002;22:5753-60

Zhao M, Tang D, Lechpammer S, Hoffman A, Asea A, Stevenson MA, Calderwood SK. Double-stranded RNA-dependent protein kinase $(\mathrm{pkr})$ is essential for thermotolerance, accumulation of HSP70, and stabilization of ARE-containing HSP70 mRNA during stress. J Biol Chem 2002;277:44539-47 